\title{
Megacystis-microcolon-intestinal hypoperistalsis syndrome: confirmation of autosomal recessive inheritance
}

\author{
R M WINTER* AND S A S KNOWLES † \\ From * the Kennedy Galton Centre, Harperbury Hospital, Herts, and Division of Inherited Metabolic \\ Disease, Clinical Research Centre, Northwick Park Hospital, Harrow: and $\doteqdot$ the Department of Perinatal \\ Pathology, John Radcliffe Hospital, Oxford.
}

SUMMARY We report two female sibs with the megacystis-microcolon-intestinal hypoperistalsis syndrome. The parents are first cousins. These cases, together with three other published reports of affected sibs, confirm the autosomal recessive inheritance of the syndrome.

Berdon et al first described what they called the megacystis-microcolon-intestinal hypoperistalsis syndrome in five female infants, two of whom were sisters. All the cases had marked dilatation of the bladder and some had hydronephrosis and the external appearance of a 'prune belly'. The infants also had microcolons and dilated small bowels, but with normal ganglion cells. Early death was a feature in all cases. Since then, several other cases have been described, in both sexes, although with a female preponderance of $4: 1 .^{2-14}$ Three possibly affected sib pairs have been described. ${ }^{1}{ }^{12}$ The purpose of this paper is to describe two female sibs with the disorder, who are the offspring of first cousin parents.

\section{Case reports}

The parents of the affected infants were first cousin gypsies. In addition to the two affected sibs described, there was one other healthy female sib.

CASE 1

The proband was born at term and died almost immediately (figs 1 and 2). Birth weight was $3 \cdot 1 \mathrm{~kg}$. Oligohydramnios was not noted during the pregnancy.

The forehead was broad and there was mild hypertelorism with a broad, prominent nasal bridge and anteverted nostrils. The mandible was extremely small and there was a U-shaped cleft palate. The ears were low set and posteriorly rotated with a deficient superior part of the helix. The chest was

Received for publication 25 May 1985.

Revised version accepted for publication 12 August 1985 narrow and the abdomen was enormously distended, with deficient musculature and a small paraumbilical hernia. Urine could be expressed from the urethra by moderate pressure on the fundus of the bladder. The genitalia were female,

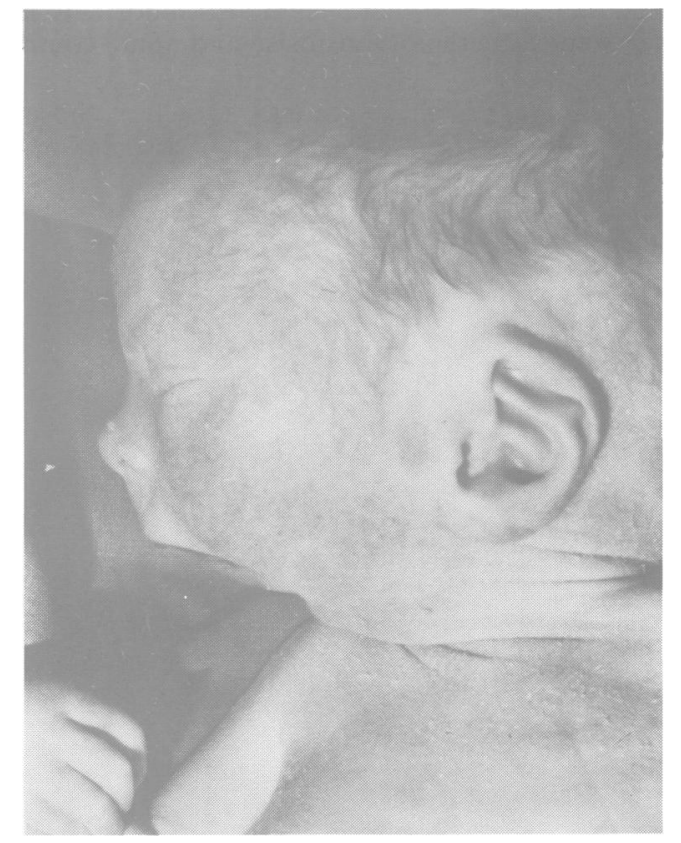

FIG 1 Case 1. Lateral facial features at birth. Note extreme mandibular hypoplasia, anteverted nares, and deficient upper part of helix. 


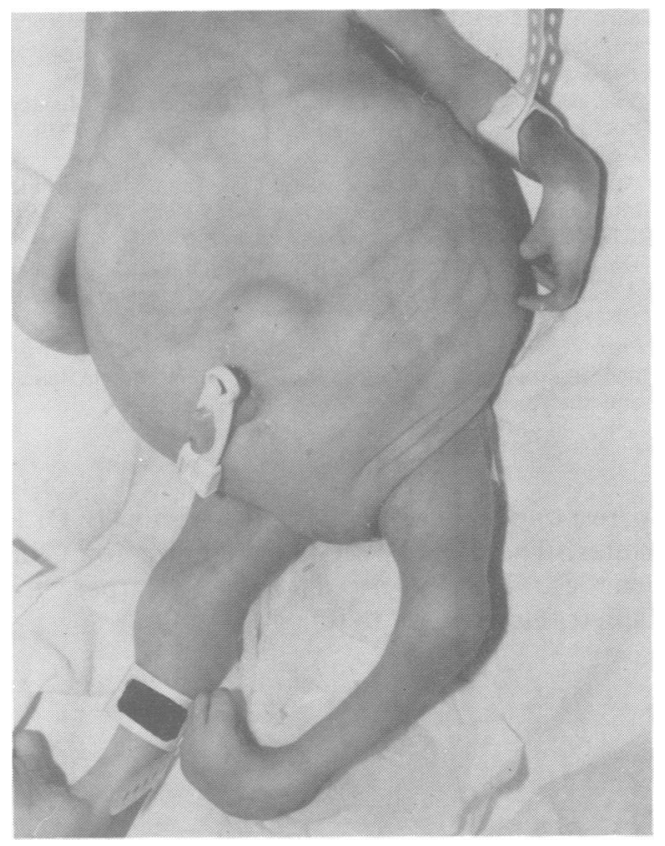

FIG 2 Case 1. Note markedly distended abdomen, multiple joint contractures with muscle hypoplasia, and severe talipes equinovarus.

but with hypoplastic labia. There was camptodactyly, with long thin fingers, contractures of the wrists and knees, and severe talipes equinovarus. The toenails were hypoplastic. Chromosome analysis ( $G$ banded) showed a normal female karyotype. Necropsy was refused.

Enquiry revealed that the parents had had a similarly affected child three years previously. A necropsy report on this child was available.

\section{CASE 2}

This female infant was born by Caesarean section at term, and died at one hour of age. Birth weight was $3: 3 \mathrm{~kg}$, length $51 \mathrm{~cm}$, and OFC $31 \mathrm{~cm}$. The face was "broad and puffy" and the ears were low set. The abdomen was described as "somewhat distended".

Necropsy showed generalised oedema. There was a truncus arteriosus overriding both ventricles. The duodenum was markedly dilated in its proximal segment and the remainder of the small intestines were high up in the abdomen and considerably shorter than normal. The caecum and appendix were located in the left hypochondrium and the colon was very short, passing straight down the left side of the abdomen into the rectum. Both kidneys were markedly hydronephrotic and the ureters were dilated and tortuous. The bladder was enormously distended and showed considerable trabeculation, but there was no evidence of urethral obstruction, and pressure on the fundus caused urine to flow readily through the urethra.

The anterior and posterior fontanelles were very large, with poor development of the occipital and frontal bones. There were multiple small foci of necrosis and calcification throughout the white matter of the brain.

\section{Discussion}

Puri et al ${ }^{11}$ have pointed out the similarity between the megacystis-microcolon-intestinal hypoperistalsis syndrome and a milder condition known as chronic idiopathic intestinal pseudo-obstruction ${ }^{15} 16$ or 'hereditary hollow visceral myopathy'. However, inheritance in the latter condition appears to be autosomal dominant. The histology of the myenteric plexus in cases of megacystis-microcolon-hypoperistalsis has mostly been reported as normal, with a few exceptions. ${ }^{1013}$ A complex heart malformation has been reported in a previous case. ${ }^{6}$

The presence of the condition in two female offspring of consanguineous parents, together with the other reports of three sets of affected sibs, ${ }^{1} 612$ strongly suggests that this syndrome is autosomal recessive. Care should be taken to distinguish this syndrome from isolated 'prune belly' caused by urethral obstruction. ${ }^{17}$ The latter condition is predominantly found in males and has a low recurrence risk. It is possible that the high female to male sex ratio in the megacystis-microcolon-intestinal hypoperistalsis syndrome is due to underdiagnosis in males, because they would tend to be misdiagnosed as isolated cases of 'prune belly' syndrome.

In view of the severe manifestations at birth and earlier, ${ }^{10}$ it is likely that prenatal diagnosis by high resolution ultrasound would be possible before 20 weeks of pregnancy in most cases.

\section{References}

' Berdon WE, Baker DH, Blanc WA, Gay B, Santulli TV, Donovan C. Megacystis-microcolon-intestinal hypoperistalsis syndrome: a new cause of intestinal obstruction in the newborn. Report of radiologic findings in five newborn girls. $A J R$ 1976;126:957-64.

2 Amoury RA, Fellows RA, Goodwin CD, Hall RT, Holder TM, Ashcraft KW. Megacystis-microcolon-intestinal hypoperistalsis syndrome: a cause of intestinal obstruction in the newborn period. J Pediatr Surg 1977;12:1063-5.

3 Wiswell TE, Rawlings JS, Wilson JL, Pettett G. Megacystismicrocolon-intestinal hypoperistalsis syndrome. Pediatrics 1979;63:805-8.

4 Young LW, Yunis EJ, Girdany BR, Sieber WK. Megacystismicrocolon-intestinal hypoperistalsis syndrome: additional clinical, radiologic, surgical and histopathologic aspects. $A J R$ 1981;137:749-55. 
5 Krook PM. Megacystis-microcolon-intestinal hypoperistalsis syndrome in a male infant. Radiology 1980;136:649-50.

- Patel R, Carty H. Megacystis-microcolon-intestinal hypoperistalsis syndrome: a rare cause of intestinal obstruction in the newborn. Br J Radiol 1980;53:249-52.

7 Hoehn W, Thomas GG, Mearadji M. Urologic evaluation of megacystis-microcolon-intestinal hypoperistalsis syndrome. Urology 1981;17:465-6.

* Sumner TE, Crowe JE, Klein A, et al. Radiological case of the month. Am J Dis Child 1981;135:67-8.

9 Jona JZ, Werlin SL. The megacystis microcolon intestinal hypoperistalsis syndrome: report of a case. J Pediatr Surg 1981;16:749-51.

10 Vezina WC, Morin FR, Winsberg F. Megacystis-microcolonintestinal hypoperistalsis syndrome: antenatal ultrasound appearance. AJR 1979;133:749-50.

1 Puri P, Lake BD, Gorman F, O'Donnell B, Nixon HH. Megacystis-microcolon-intestinal hypoperistalsis syndrome: a visceral myopathy. J Pediatr Surg 1983;18:64-9.

12 Oliveira G, Boechat MI, Ferreira MA. Megacystis-microcolonintestinal hypoperistalsis syndrome in a newborn girl whose brother had prune belly syndrome: common pathogenesis? Pediatr Radiol 1983;13:294-6.
13 Kirtane J, Talwalker V, Dastur DK. Megacystis, microcolon, $\stackrel{\mathbb{D}}{\longrightarrow}$ intestinal hypoperistalsis syndrome: possible pathogenesis. $J \overrightarrow{\overline{\vec{A}}}$ Pediatr Surg 1984;19:206-8.

14 Vinograd I, Mogle P, Lernau OZ, Nissan S. Megacystismicrocolon-intestinal hypoperistalsis syndrome. Arch Dis Child 1984;59:169-71.

15 Anuras S, Shaw A, Christensen J. The familial syndromes of intestinal pseudoobstruction. Am J Hum Genet 1981;33:584-91. ¿

16 Schuffler MD, Rohrmann CA, Chaffer RG, Brand DL, ֶ Delaney JH, Young JH. Chronic intestinal pseudo-obstruction. A report of 27 cases and review of the literature. Medicine $\vec{O}$ 1981;60:173-96.

17 Pagon RA, Smith DW, Shepard TH. Urethral obstruction malformation complex: a cause of abdominal muscle deficiency $O$ and the 'prune belly'. J Pediatr 1979;94:900-6.

Correspondence and requests for reprints to $\mathrm{Dr} R \mathrm{M}$ Winter, The Kennedy Galton Centre for Clinicalo Genetics, Harperbury Hospital, Harper Lane, Radlett, Herts WD7 9HQ. 